announcements (continued from page 1057)

\section{Deadlines Calendar}

Fellowships, grants etc.

15 September applications for Fulbright Scholar Awards for 1988

Africa, Asia, Europe, the Middle East, and lecturing awards to Mexico, Venezuela, and the Caribbean

(April 1988 Bulletin, p. 408)

1 October 1988 applications for NOAA meteorologist, GS(GM)-1340-5/15, positions (this issue, p. 1067)

31 October 1988 requests for financial aid for Course on Tropical Ocean-Atmosphere Interactions (13 February-10 March 1989), Fortazela, Brazil (this issue, p. 1067)

1 November 1988 applications for institutional proposals for the Scholar-in-Residence Program of the Fulbright Scholar Awards (April 1988 Bulletin, p. 408)

30 November 1988

requests for participation in Course on Tropical Ocean-Atmosphere Interactions (13

February-10 March 1989), Fortazela, Brazil (this issue, p. 1067)

30 November 1988

1 January 1989

1 February 1989 applications for NCIM fellowships (summer 1989)

(this issue, p. 1067)

applications for Administrator's awards of the Fulbright Scholar Awards in Germany, the United Kingdom, and Japan, the seminar in German Civilization, the NATO Research Fellowships, and the Spain Research Fellowships

(April 1988 Bulletin, p. 408)

applications for the France, Italy, and

Germany Travel-Only Awards

(April 1988 Bulletin, p. 408)

\section{index to advertisers}

c2 Alden Electronics

c3 Atmospheric Instrumentation Research (AIR)

c4 Belfort Instrument Company

1075 Lockheed

1081 Qualimetrics, Inc.

1084 R-Scan

1075 Southeastern Center for Electrical Education (SCEE)

1076 Technology Service Corporation

1083 Teledyne

1087 Vaisala, Inc.

1091 Weatherwise

1082 R. M. Young Company

1077 Zephyr Weather Information Services

\section{AMS Publications, Preprints, etc.}

1080 AMS Lapel Pin/Tie Tack

1086 Handbook of Applied Meteorology

1086 Probing the Atmospheric Boundary Layer

1090 Lectures on Air Pollution Modeling

1107 AMS Newsletter

\title{
candidates for CCM
}

The candidates named below have met the qualifications required by the Board of Certified Consulting Meteorologists and the Commission on Professional Affairs of the American Meteorological Society.
Board procedures require publication of the names of candidates in the Bulletin, and if no objection to the action of the Board and Commission on Professional Affairs is submitted within 60 days of publication, the approval is final.

Philip J. Galvin, 4 Hiawatha Drive, Clifton Park, NY

Montie M. Orgill, 904 Lenox, Las Cruces, NM 88005

George Schewe, 939 Garnoa, Cincinnati, OH 45231

Anthony O. Johnson, 11003 Brightside Dr., Tampa, FL 33624

Willard J. Pierson, Jr., 103 Oakland Ave., West Hempstead, NY 11552 